\title{
ADELARDO DE BATH SOBRE LO IDÉNTICO Y LO DIFERENTE*
}

\author{
Pedro Mantas España \\ Universidad de Córdoba
}

\section{TRADUCCIÓN, segunda parte ${ }^{1}$}

(PHILOSOPHIA) «Oh joven, con un triunfo nada indigno me has enriquecido. Desde hace tiempo esto mismo había esperado de ti, cuando, todavía niño, te acogiste a mis estudios con tanto afecto. Pues ahora que nos has liberado tanto a mí como a ti mismo de tal monstruo [Philocosmia], no es conveniente que te alejes sin un obsequio. Pues con una iniciación tal, no hay duda que puedo confiar en lo que resta de ti.

Tengo aquí conmigo estas siete doncellas, sus naturalezas y caracteres explicaré individualmente para que así elijas por decisión propia cuál de todas prefieres para ti. Porque abrazarlas todas al mismo tiempo sería más de lo que tu ingenio es capaz.

* Introducción y traducción de Pedro Mantas España.

1 Texto: un único manuscrito conocido, Adelardus Bathensis, De eodem et diverso, Ms. Paris, Bibliothèque nationale, lat. 2389, fols. 82v-91v (S. XII). Ediciones: H. Willner ed., en «Des Adelard von Bath Traktat», Beiträge zur Geschichte der Philosophie (und Theologie) des Mittelalters, IV.1, Münster 1903; C. Burnett ed., en Adelard of Bath's Conversations with His Nephew: "On the Same and the Different», "Questions on Natural Science» and "On Birds», edición latina (Burnett ed. DED) y traducción al inglés (Burnett trad. DED), Cambridge Univ. Press, 1998.

Para la $1^{\text {a }}$ parte de la traducción, véase Revista Española de Filosofía Medieval, 5, Zaragoza, 1998, pp. 249-64. 
(GRAMÁTICA) Y así esta primera, a quien ves llevando un látigo en su mano derecha y un códice anotado con innumerables correcciones en su mano izquierda, nutre en sus cunas a los que entran en las artes liberales e introduce la primera leche en sus bocas. Sin su alimento, en balde acercas tus manos a la sabiduría, hasta tal punto, que los despojados de ella, aún estando dotados de cierta prudencia, no sin merecerlo serán llamados simples tartamudos. Pero aquellos que han sido atrapados en su red, no lo dudes, exceden a otros hombres por el arte racional de la elocuencia, tanto como los hombres exceden a las bestias por sus dotes para el razonamiento. ${ }^{2}$ Porque esta dama, cuando en un principio los mortales deambulaban de aquí para allá como bestias en el campo, sin la acostumbrada cortesía mutua y con la razón en silencio, y sin que alguno pudiese insinuar a otro lo que comprendía, ya fuese sobre sí mismo o sobre las cosas de alrededor - ésta, digo, al imponer nombres a las cosas singulares, bendijo por primera vez a los mortales con la dignidad de la conversación mutua.

Si pones tu mente en ello, te darás cuenta qué trabajo tan difícil es éste, pues las cosas no sólo son infinitas en número, sino que además han de ser nombradas, o bien en sí mismas, o en conjunción, o en cómo son comprendidas como universales, o en cómo están sujetas a una propiedad individual, al estar sometidas a los sentidos. Por ejemplo, aquello que es un accidente en un sujeto cuerpo, al ser concebido en sí mismo, como si fuese una cierta sustancia no referida al cuerpo, se lo llamó «blancura», pero cuando lo es en un sujeto, se lo designó por medio del nombre «blanco». Lo mismo que el animal racional al que miras, al ser comprendido en la universalidad de la definición sustancial es juzgado como «hombre», pero en tanto que es desvelado por la singularidad de una descripción, es llamado «Sócrates». Habiendo vestido así las cosas con nombres, ella ha impuesto diferentes términos a los términos mismos, ${ }^{3}$ de modo que incluso las diferencias entre ellos mismos no quedarían ocultas y esa múltiple infinitud, habiendo sido reducida por medio de un número, no quedaría privada de ser comprendida por una ciencia. Así, con hermosa sagacidad enlaza esa totalidad con el conjunto de las ocho partes del discurso; hasta tal punto no atempera ella la perfección de la imposición que, del mismo modo que un término puede significar una cosa, así también un término puede significar un término. Por ejemplo, en la frase «un hombre anda», el término que actúa como sujeto se refiere a la cosa que anda. Pero, cuando propongo la frase «'hombre' es un nombre», no es una cosa sino un término lo

2 Este pasaje evoca el De inventione de Cicerón (I, 4, 5).

3 Decíamos en n. 36 (véase Traducción $1^{\circ}$ parte) que optábamos por traducir «vox» como «voz». Ahora, en el contexto específico de «Gramática», he adoptado la traducción de «vox» como «término». Ciertamente, esta alteración no constituye un procedimiento muy ortodoxo, pero las implicaciones interpretativas que transmite este fragmento están involucradas en el debate (todavía hoy abierto) en torno a las escuelas, diferencias y raíces del vocalismo y nominalismo en la primera mitad del s. XII; pienso que traducir por «término» puede contribuir a mantener abierta la cuestión (para una introducción sobre este problema en Adelardo, véase P. Mantas España, Adelardo de Bath, Madrid, 1998, pp.31-8). 
que se significa por medio del término que actúa como sujeto. Nombrando este término «hombre» por sí mismo, indico que tiene la propiedad de un nombre. He aquí que el laberinto aflora, que en un término que actúa como sujeto, tanto el significado como el significante son la misma cosa, lo que algunos han llamado, finalmente, «imposición material». ${ }^{4}$

Esta misma doncella, inculcando gratamente sus preceptos en uno de sus discípulos, comenzando la enseñanza a partir de la letra, e instruyéndolo después a combinar las letras en sílabas, las sílabas en palabras y las palabras en construcciones perfectas, atrajo para sí una fama tan extensa como duradera. Pero esto entre los de habla latina. Que si hubiese alguien capaz de abrazar la totalidad de su arte, no se le ocultaría todo aquello que es frecuente en los escritos afines a griegos y bárbaros 0 a cualesquiera de los mortales. Ya ves cuán importante es. Todavía podría proferir sobre ella muchas alabanzas no menos dignas, mas a ti tampoco te es enteramente desconocida y, con no menos prontitud, he de repasar los atributos de las doncellas que restan.

(RETÓRICA) En consecuencia, esta que distingues en segundo lugar, con alegre gozo en su rostro y noble confianza en el semblante, como dispuesta para decir algo, y a cuyo vestido está cosido todo lo que pueda acontecer en el debate civil, ${ }^{5}$ no puede ser, creo, suficientemente elogiada ni por mí ni por cualquier otro. Pues, como he dicho antes, cuando los hombres habían sido iniciados en la exposición mutua de lo que hay en sus mentes, esta dama, añadiendo su propia contribución, adornó con un ornamento dulcemente sonoro de palabras y frases todos los discursos de aquellos que habían adquirido la facultad de hablar, con la misma ágil sutilidad que aquella con la que fue inventada el habla. De ahí que aquellos que al principio vivían confusamente y sin justicia legal, fueron impulsados hacia la ciudadanía y la justicia comunitaria por una incitación tan poderosa. ${ }^{6}$ Así pues, cualquier cosa honorable que ha surgido del acuerdo entre ciudadanos, considero que debe ser adscrito a esta dama.

Luego, ¿quién puede dudar de la fuerza que ella tiene para refrenar los impulsos irracionales de los modernos tiranos, cuando fue ella quien primero impulsó a los mortales, inflexibles en toda crueldad, hacia la humanidad y el compañerismo? No ignorando su poder, Sócrates ${ }^{7}$ dispuso toda la organización de

4 La «imposición material» 0 «segunda imposición» que se menciona Adelardo se refiere a un proceso bien conocido entre los gramáticos del s. XII y al que hacen alusión distintos maestros (véase Juan de Salisbury, Metalogicon, ed. C.C.J. Webb, Oxford, 1929, p. 142.22-4); el ejemplo que Adelardo ha mostrado en líneas anteriores es un caso característico. Para una introducción a distintos problemas derivados de la «gramática» y su vinculación con ciertas cuestiones «lógicas», véase Fredborg, K. M., «Speculative Grammar», Tweedale, M. M., «Logic (i): form the late 11 th. century to the time of Abelard, y Jacobi, K., Logic (ii): the later 12th. century, en P. Dronke, ed. A History of Twelfth-Century Western Philosophy, Cambridge, 1992, pp. 177-195; pp. 196-226; pp. 227-251.

5 «Civilis diceptatio» (cf. Cicerón, De inventione, I, 5, 7).

6 Ibídem, I, 1,2.

7 Adelardo sigue a Cicerón (De inventione, 1, 5, 7), pero no es Sócrates sino Aristóteles la autoridad a quien cita Cicerón. En Burnett trad. DED (n. 36) se cita a Anselmo de Laon -a partir del Comentario al De inventione de Guillermo de Champeaux- como una fuente adicional y crítica sobre la localización de los tres géneros de la retórica. 
la cosa pública bajo su autoridad, subordinando tres tipos de disputa a los tres géneros de la retórica. Por ello, una causa era juzgada en el Capitolio, y era llamada «deliberativa»; o en el Campo de Marte, y «demostrativa»; 0 en el Foro, y «judicial». Entonces, el mismo filósofo, ${ }^{8}$ ampliando la causa, la clasificó en cinco partes, enseñando a descubrir argumentos, a ordenar lo descubierto, a exponer lo ordenado, y a usar la memoria y la declamación en la exposición. Si ella instruye a alguien por completo en esto, cualquiera que sea la causa razonable que uno emprenda, ella le hace salir victorioso, entregándose con tanta persuasión, que cuando ella ha inclinado la mente de los jueces a favorecer los argumentos de la acusación, si ella se cambia a la parte contraria, con no menos verosimilitud induce a refutar la otra parte. De aquí que los griegos la denominaron, antes que al resto de las artes, «rhetorica», esto es, elocuencia. ${ }^{9}$ Como es natural, cualquiera que se pertreche de ella será tan querido por sus amigos como temido por sus enemigos, por tanto, no sólo es respetada en el filósofo sino también entre los que ignoran las letras, que más consultado es, y más a menudo, quien parece ser más elocuente que otros por su mayor dominio de la palabra. De aquí que en muchísimos tribunales los rústicos elocuentes sean preferidos a los filósofos silenciosos.

De su poder en el filósofo no es digno dudar -no precisamente por ti, que no ignoras cuán grande fue la fama con que ella honró a Tulio Cicerón, con qué honor le hizo avanzar, con qué dignidad lo llevó a lo alto, pues ella le afiló su lengua como un cuchillo, y le hizo ser temido por todos sus conciudadanos. $Y$ de la influencia que tuvo ante los emperadores todavía dudas menos, cuando lees en sus discursos lo que dio de sí en presencia de César - ciertamente, al mismo que había declarado su lealtad al partido de la oposición y juzgado a César como enemigo de la República, sólo por el poder conciliador de la elocuencia, Cesar lo trató amistosamente. Después, como orador, restauró la dignidad de Marco Marcelo; como defensor, liberó a Quinto Ligario de la pena capital y liberó a Deiotaro del odio de Cesar. ${ }^{10}$ De éstos, algunos habían planeado a traición el asesinato del Emperador, otros se habían pronunciado en contra de sus ejércitos. Pero Cesar no tuvo de qué acusar cuando Tulio los defendiera, nada que objetar cuando con tanta elocuencia rogase el perdón. Por lo que Cesar, a quien un millar de tropas no habían perturbado, en presencia de un retórico se olvidó de sí mismo y quedó desprovisto de ánimo. Del mismo modo que él, cuando vencedor, sobrepasara a aquellos que había derrotado, en igual medida el orador había de sobrepasarlo a él, ahora derrotado. De aquí que el mismo Cicerón a veces exclamase: «Cedan las armas a la toga,

8 Cicerón, De inventione, I, 7, 9.

9 Ibidem, I, 5, 6.

10 La referencia de Adelardo son los «discursos forenses» de Cicerón más conocidos en la Edad Media (Pro Marcello, Pro Ligario y Pro rege Deiotaro). 
concede a la lengua la corona de laurel. $\rangle^{11}$ Pues, incluso entre los enemigos, esta lengua tenía tanto valor que llegó a ser el precio de la paz para todo el Imperio; ni Antonio dudó en hacer alianza con Cesar, con tal que le cediese la lengua del orador. Le temía más a su elocuencia que a las armas de Roma, y no se habría sentido protegido en la paz de Cesar, mientras Cicerón escribiese contra él.

No hay duda, pues, cuán valiosa es la doncella que de este modo exalta a los suyos. No en vano, comprendiendo esto mismo, Aristóteles veló mucho por sus preceptos, enseñando que cualquier caso es de género honorable o deshonroso o despreciable o equívoco u oscuro, ${ }^{12}$ mostrando las concomitancias y diferencias entre cada uno de ellos, y cómo se habría de iniciar un discurso en cada caso - pues no se hace lo mismo en todos ellos. En ese escrito se añade aquel lúcido tratado que versa sobre el motivo por el que, en la especie escandalosa del género «deshonroso», ${ }_{13}^{13}$ los oyentes son impulsados a la benevolencia, la docilidad y la atención, mientras los oponentes, hacia el odio, la envidia y el desprecio, lo que produce no poco efecto en toda discusión de este tipo. Pero el mismo filósofo tampoco guarda silencio a cerca de la subdivisión de las mismas especies, diciendo que el asunto es, en cada caso, «conjetural» 0 «definido» 0 «general» 0 «transferido». ${ }^{14}$ Alguien que sin reticencias vuelva a leer sobre cada uno de éstos, llegará a estar pleno de una grata cordialidad. El hombre sabio se consagra diligentemente a la labor de definir estos y todos los demás preceptos de este arte, comprendiendo cuánta utilidad y honor es alcanzado por quien los practica, considerando la nobleza del asunto. Y llegamos al final de lo que se dice sobre esta doncella; pasemos ahora a las que restan.

(DIALÉCTICA) Esta tercera doncella que ves, portando una serpiente en su mano derecha y en la izquierda un códice en el que se representan algo así como diez distinciones, es, después de las ya mencionadas, muy necesaria para los mortales. Pues, por criterio suyo, determina todo lo ambiguo y dudoso que acostumbra a surgir a partir de los preceptos de las artes ya mencionadas, y reduce a certeza un intrincado cruce de caminos. Ella, excluyendo cualquier engaño verbal, deshace, por medio de precisas divisiones, las trampas de los sofistas y forja la

11 Cicerón, De officiis, I, 22, 77; In Pisonem, 72, 22. Quintiliano, Institutio Oratoria, XI, 1, 24;

12 La fuente no es Aristóteles sino Cicerón (cf. De inventione, I, 15, 20).

13 «[...] in turpi ammirabilis generis specie». Como anota Burnett (Burnett trad. DED, n. 41), el término «admirabilis» ha de traducirse como «deshonroso» pues aunque su significado es el de «admirable» 0 «maravilloso», en realidad y dadas las características que presenta entre los tipos de exposición ante los tribunales, posee el sentido de «difícil»; no obstante, se trata de un término con un significado muy preciso en retórica y, según parece, los historiadores optan por traducirlo como «deshonroso». Por lo que se refiere a (turpi specie) «especie escandalosa», no parece correcto que Adelardo haya relacionado «turpi» con «admirabilis» pues Cicerón habla de la «insinuatio» como el tipo de introducción apropiada para un caso del género «admirabilis». Sin embargo, en De inventione, I, 17, 23, Cicerón explica que un caso de género «admirabilis» surge a partir de tres tipos de causas, y se refiere a «turpido» (escándalo) como la primera de ellas.

14 Cicerón, De inventione, I, 8, 10. 
verdad, enseñando que todo aquello que puede confundir en las palabras es equívoco o unívoco, o de diferente parte o diferente tiempo o diferente consideración o diferente modo; en sus Categorías, ${ }^{15}$ Boecio decidió que esto no sería omitido. Esta misma doncella mantiene sometida a la invención y el juicio y, por medio de éstos, resuelve todas las disputas que surgen en su negocio. Pues cuando una cuestión ha sido propuesta, ella juzga en un primer examen, qué parte de la cuestión habrá de ser retenida y cuál rechazada. Para confirmar ese juicio, no se fatiga en descubrir recursos con sus argumentos, aunque a algunos les parezca mejor que la invención preceda al juicio. Por medio de una sutil investigación, ella misma ha dividido en diez naturalezas la suma de todo lo que se ve, alegando que sólo hay diez modos diferentes de ser en las cosas de naturaleza completamente diferente - que desde entonces también se denominaron «diez categorías»- y añade el género, la especie y el individuo a cada categoría. ${ }^{16} \mathrm{Y}$ explica que, del género, algunas son «más generales» y otras «subordinadas»; explica, así mismo, que de la especie, algunas son «más especiales» y otras «subordinadas», dando ese dignísimo paso alterno para que, ahora, se ascienda desde lo individual hasta lo más general a través de lo intermedio, expoliando —en realidad, olvidando - las propiedades y, después, se descienda con los mismos pasos, desde el género más general hasta los individuos, desvelando las formas de cada uno. Naturalmente, acariciando el rostro de la naturaleza universal de las cosas con la hermosa sutileza de su luz, ella se afana por mantenerlas del modo en que fueron concebidas previamente en la mente del Artesano; considera los accidentes sin su relación con las sustancias; separa también las diferencias de los accidentes mismos, habiendo confiado, obviamente, en esta sutileza, y así, al usar afilados y molestos argumentos, los atrapa de improviso hacia ella como una serpiente, y segura en su defensa de la determinación, desprecia los dardos lanzados por otros.

De donde resulta que, si alguien ha alcanzado su estado de ánimo, no ignoraría qué proposición es verdadera, cuál es falsa y, de estas mismas proposiciones, cuál posee una determinada verdad o falsedad, y cuál de ellas posee una verdad incierta o dudosa; del mismo modo, qué argumentos son probables, cuáles necesarios, cuáles sofísticos; y de los tópicos, cuáles son intrínsecos, cuáles extrínsecos, cuáles intermedios; y de la división, cuáles son de acuerdo a ellos mismos, cuáles de acuerdo a los accidentes; y de las definiciones, cuáles sustanciales, cuáles accidentales; y también las variedades, figuras y

15. Boecio, Introductio ad syllogismos categoricos, PL, 64, cols 761-94 (véase cols. 778-9); aunque para la referencia de Adelardo a lo «univoco», véase Boecio, In librum Aristotelis De Interpretatione, editio secunda, 2, PL , 64, col. 460D.

16 Véase el «Comentario» de Boecio a la Isagoge de Porfirio, eds. S. Brandt y G. Schepss, en Corpus scriptorum ecclesiasticorum latinorum, 48, Viena y Leipzig, 1906, pp. 44-4, 180-1, 211-6. 
modos del silogismo. Empapado en estas sutilezas, siempre que Aristóteles deseaba gastar una broma, en presencia de otros y sirviéndose de recursos sofísticos, construía un falso argumento con no menos poder del que tenían los demás para, frente a él, defender la verdad misma. De hecho, así como las otras artes, cuando dependen del auxilio de ésta, permanecen impertérritas en sus argumentos, de igual modo, sin su auxilio, titubean e ignoran la estabilidad. De donde también resulta que, entre los modernos, son particularmente respetados por su talento para hablar, aquellos que son más eminentes que otros en este arte. Y porque hasta aquí se ha demostrado lo que concierne a estas tres artes cuyos preceptos se mueven en torno a las palabras, es preciso no guardar silencio a cerca de las cuatro restantes, que disputan sobre las cosas mismas.

(ARITMÉTICA) Así, la primera de éstas es, por cierta excelencia, superior a las otras tres que le son afines; en su túnica ves tejidos innumerables caracteres que representan números, y lo mismo ordena que dirige todo aquello que se somete a la distinción del número. Pues ocurre que, así como el universo visible está sujeto al número, así también ha de estar necesariamente sujeto a ella. Porque todo lo que es, o es uno o múltiple. ${ }^{17}$ Ella delimita la misma inconmensurable universalidad por el límite de un término, que es cierto para ella misma y para la naturaleza. Si se la excluye, la pluralidad de las cosas singulares es confusa e incierta, lo que cualquiera puede entender claramente, pues si alguien olvida completamente el número de sus posesiones, las concibe confusamente y sin delimitación. De aquí que no sólo hable de lo necesaria que ella resulta para estas doncellas que ves a su lado, ni tampoco dude que habría de ser preferida a todas las esencias, pues al liberarlas de la confusión, les aporta distinción. Porque el número, cuya propia naturaleza ella conoce y explica, de tal modo incumbe a las propias cosas que lo ordenado a partir de una inicial confusión, recibe su encanto a partir de su ejemplo y buen parecer. Comprendiéndolo así también, Jenócrates definió el alma misma como número, diciendo: «El alma es número que se mueve a sí mismo». ${ }^{18}$ Esto que tan gran filósofo con tanta brevedad ha expresado, tal vez es dudoso para ti. ¿Seguro que no entendió que el número era distinto del alma? ¿Seguro que no juzgó que el accidente es esencialmente el mismo que su sujeto? ¿Seguro que, como el número es compuesto, no se equivoca al decir que el alma misma sea compuesta? ¡ De ninguna manera! Por el contrario, dado que encuentra que nada hay en las cosas cuya esencia tenga tanta dignidad como el número, buscando algo que com-

17 «Quicquid enim est, aut unum aut plura est»; en el contexto temático de la obra de Adelardo sobre «lo idéntico y lo diferente» o «lo mismo y lo otro», es interesante constatar que, en este pasaje, nuestro autor no sigue a Boecio, quien constantemente afirma que «todo lo que es, lo es por ser uno» (cf. Boecio, In Porphirium, PL 64, 83) o también que «esse enim atque unum convertitur, et quodcunque est, unum est» (cf. Boecio, Liber de persona et duabus naturis, PL 64, 1346A).

18 Burnett hace notar (Burnett trad. DED, n. 47) que Adelardo conoció esta definición a través de Nemesio (cf. Premnon phisicon, trad. Alfano, ed. C. Burkhard, Leipzig, 1917, cap. 2, pp. 40-1). 
parar con el alma, identifica el número con el alma - a buen seguro que apoyándose en su semejanza, la llamó «número». Para que ningún cazador de palabras piense que el alma es esencialmente eso mismo que ella había dicho, añadió a la definición el «se mueve así mismo», pues aunque ningún número se mueve a sí mismo y, no obstante, el alma si se mueve a sí misma, no entendamos por ello que el alma es número, sino que posee tal dignidad respecto a las demás cosas como la que se dice que el número tiene respecto a ella. Pero volvamos al asunto.

Del número mismo, yo afirmo que esta doncella que describo es la maestra y la que lo da a conocer. Tomemos familiaridad con ella: es esta misma a la que los griegos, precursores del arte de todas las cosas, llamaron «aritmética», que es como decir «perfección propia del número»; entendiendo, a un tiempo, que el ser propio de la perfección de las cosas está en los números y que, como dueña, ella misma gobierna por encima de tal dignidad. Efectivamente, al principio $^{19}$ define el número y, después, lo determina como una suma de unidades 0 un cúmulo de cantidad surgido de las unidades. En verdad, después de la definición, que debe preceder el comienzo de cualquier tratado, añade la división, separando el número en par e impar; después, distingue estas especies con una definición precisa según las cualidades contrarias de los dos géneros - es decir, multitud y magnitud. Posteriormente, realiza una subdivisión de estas mismas especies, mostrando que un número par es, por una parte, «par de modo par», por otra, «impar de modo par» y, por otra, «par de modo impar». Llama a esta primera especie de subdivisión «aquella cuyas partes, al ser subdivididas, son divididas en pares hasta su encuentro con la unidad». Por «impar de modo par» entiende aquel número cuya primera división se realiza entre números iguales, pero la proxima vez sus cocientes resultan ser indivisibles; en el «par de modo impar», también se divide en partes iguales y sus cocientes también son pares, sin embargo esta división no llega hasta la unidad y falla antes de alcanzarla, y así, ni su primer término es el único divisible en partes iguales, ni sólo su último término queda excluido de la división. Estas cosas que tanta alegría producen a quienes las entienden son puestas claramente ante la vista en aquella figura descriptiva que Nicómaco y sus seguidores llamaron «admirable». ${ }^{20}$ Con no menos exactitud, ella divide también en tres partes la otra especie de número, diciendo:

«De los números impares, uno es primo e incompuesto, otro es secundario y compuesto, otro, un número que de algún modo está formado y consta de ambos. En efecto, es un número secundario y compuesto por sí mismo, pero al compararlo con otros resulta ser primo e incompuesto.. ${ }^{21}$

19 La exposición que sigue es un resumen de las definiciones que ofrece Boecio en De arithmetica, I, 3-19; 28).

20 lbidem, I, 28.

21 Ibídem, I, 13. 
Tampoco ha improvisado descripciones de estas tres partes, y revela que su origen brota, como de una asombrosa fuente, a partir del número tres, lo que tanto Eratóstenes como sus seguidores llamaron la «criba». ${ }^{22}$ Del mismo modo, añade otra no menos digna división de ese mismo número par, enseñando que algunos son insuficientes, otros sobreabundantes y otros, entre aquellos y éstos, perfectos. Lo rico y fecundo de este procedimiento no puede hacérsele manifiesto sino a aquel ante quien ella misma realiza una demostración. Las demás florituras que hay en ella, ni ahora me parece oportuno enumerarlas, ni a ti te resultaría fácil comprenderlas, a menos que estuvieses presente en clase. En cualquier caso, sólo esto sé: que sus preceptos requieren de un experto dedicado por entero a ella y a olvidarse de todo lo exterior - lo que no es pequeño indicio de su exquisitez frente a las otras damas. En cualquier caso, pasemos a describir a estas otras.

(MÚSICA) Esta dama que parece superar a las demás por una cierta alegría, sostiene en su mano derecha un címbalo de dulce sonido, sin embargo, en su izquierda porta un libro que contiene los preceptos y naturalezas de todos los sonidos: ésta, digo, es reconocida como aquella que gobierna toda consonancia, y no sólo produce aquellas melodías de la voz humana que son controladas y conformes a la naturaleza, sino que también es poderosa y manifiesta su fuerza en los instrumentos de cuerda, viento y martillo. De aquí que, por un cierto poder no pequeño, hace que todas las almas se vuelvan hacia ella. En efecto, ella cautiva las mentes de los niños tan pronto como aquellas irrumpen en los cuerpos, y las sujeta con tanta fuerza que, con las primeras voces que han oído en su estado corporal, se deleitan si éstas son armónicas y se enfadan si no son acordes. Y esto, ni se da por el uso ni la naturaleza lo podría producir, a no ser que aquellas mentes ya hubiesen ingerido algo así en el cielo. Sus nodrizas, habiéndolo comprendido apropiadamente desde hace tiempo, cuando sienten que los niños se disponen a llorar por alguna causa, inmediatamente acuden a ellos con la moduláción musical de algún son. Ciertamente, el alma reservó para sí este alivio único y familiar y, en verdad, tan pronto como se le proporciona, olvida todo lo demás para deleitarse en ello. Y para que esta larga búsqueda de un ejemplo no nos canse más, puedes recordar que el año pasado, durante tus estudios en Francia, cuando tú mismo pusiste todo tu empeño en la música, y cuando una tarde, en presencia del maestro de este arte y sus alumnos, tocaste la cítara por ruego de aquellos y de su reina; a un niño, enredado en la pronunciación insegura de la palabras, le hizo tanta gracia el sonido de la cítara que empezó a mover sus manos y sus dedos a un tiempo, provocando la risa de todos los presentes. Pero no todos comprendían de manera semejante la fuerza de la música y la causa de su reacción. 
Date cuenta de hasta qué punto la adolescencia y la juventud se encuentran cautivadas naturalmente por la música que, en tiempos de paz, a ella se dedican por entero y, en tiempo de guerra, es ella la que les impone estímulos para la batalla o frenos para el ataque. Porque en el ataque, los agudos clarines estimulan los ánimos y, en la retirada, la tuba más grave apacigua los mismos ánimos. ¡Hasta tal punto domina al alma esta fuerza! $\mathrm{Y}$ aunque pase por alto hechos fabulosos - de murallas derribadas con instrumentos musicales y de bosques siguiendo a un músico tocando- esto al menos no es dudoso para quien pudiese hacer memoria de su disfrute: que la música misma dispone al alma desde la turbación hacia la quietud, así como de la quietud a la piedad. En verdad que, a la vejez, tanta eficacia tiene este ornamento, que en esa edad no sólo se reclama la armonía de los sonidos sino que la vejez se alegra y se esfuerza en conducir las costumbres y todas las acciones hacia una armonía ética. De ahí que esta edad sea denominada por muchos sabios como «grave», al tener firmemente constituida esa intención. Pues, en todas las edades, la fuerza de la música incita a transitar no sólo de la avaricia a la generosidad sino, también, de la enfermedad a la salud; no era el menor de los argumentos para los filósofos que el alma, al descender brevemente desde las estrellas superiores a los cuerpos, reconocía allí la sinfonía a que estaba acostumbrada en los cielos. Y.esto entre los seres racionales. Aunque también en los animales mudos, esta misma fuerza tiene un efecto no pequeño. Entre los ingleses, los peces son obligados a ir nadando hacia las redes mediante el dulce sonido de un címbalo sobre el agua. Entre los partos, los cantos de los hombres mismos obligan a los gamos a caer en sueños sin ningún tipo de lazo. No es dudoso que, con canciones, se atrae a los pájaros a la red. E incluso a ti, mientras disputabas sobre esto mismo, te he oído afirmar esto: que el halcón salvaje al que no podías someter de otra manera- habías domesticado con un instrumento musical. Es por ello que el mismo filósofo dijo que el Alma del Mundo estaba compuesta por dichas consonancias, no porque lo entendiese de ese modo y aisladamente, sino asumiendo que, así como el alma tiene muchas facultades, ese poder está entre los más dignos suyos, y que ella está en armonía consigo misma y se alegra al infundir igual armonía en los cuerpos; según esto, y porque ve armoniosas las partes de un cuerpo, ejercita sus poderes en ellas. Y sucede también que nunca deja de animar ese cuerpo, mientras que abandona por más tiempo a aquellos otros sin alma.

Pitágoras no pasó por alto este mismo hecho, y cuando investigaba con gran empeño las divisiones de la música - para que esto no quedase oculto a la posteridad— solía escribir sus hallazgos: ${ }^{23}$ describiendo, primero, un tipo de música cósmica, otra humana y otra instrumental - pues ni las cualidades de los elementos, ni las medidas, ni las distancias de los tiempos están alejadas 
de esta concordancia. Después, exponiendo cuáles entre la multitud innumerable de intervalos merecen el nombre de «consonancias», las redujo a un número pequeño y definido (según el principio de «todo lo precioso es escaso»), ${ }^{24}$ y las dividió, no mediante el juicio de los sentidos - con el que no se percibe sutileza alguna - sino mediante el juicio racional. Como quiera que él mismo comprendiera la ciencia de la música como aplicación de la razón a los diferentes sonidos producidos por los martillos, a partir de aquí se dedicó a estudiar los demás instrumentos de modo matemático. Pues en todas las cosas hay una misma ley de la armonía: que las proporciones de peso en los martillos y campanas producen los mismos intervalos como proporciones equivalentes de longitud y brevedad, o tensión y holgura en las cuerdas, o profundidad y amplitud en los orificios de las flautas, y lo mismo para cualquier medio que es conforme a un tipo de disonancia consonante. Todas estas cosas las persigue cuidadosamente el hombre sabio y, después, añade las diferencias entre las consonancias mismas. En su libro se subraya aquella nada despreciable afirmación que muestra cómo un tono consta de dos semitonos y una coma, y el modo en que los semitonos y la coma, de alguna forma se distinguen entre sí - pues no son iguales. ¡Debe dar las gracias a su cerebro quien lo haya entendido fácilmente! Sobre la división de los monocordes y otros asuntos del mismo género, sugirió no menos dulzuras. Si persistiera en enumerarlas, mi fuerza se agotaría con más rapidez que el número de los acontecimientos. Ahora, prosigamos ordenadamente con las restantes artes, mas no debo olvidar mencionar que, aunque tanto la aritmética como la música usan el razonamiento de los números en sus tratados, no obstante hay diferencia, pues la primera investiga primordialmente los números y, la segunda, las proporciones, aunque es evidente que los números y las proporciones no pueden separarse en tanto que añadidos a los cuerpos.

(GEOMETRÍA) Aunque estas dos doncellas que restan son desiguales en tamaño, a pesar de todo, la menor ofrece ayuda a la mayor. De hecho, también difieren en que mientras una y otra profesan la magnitud corpórea, según su oficio, la menor practica la ciencia de la magnitud inmóvil, mientras que la mayor indaga la situación del gran cuerpo celeste y móvil. De aquí que fue la menor, que es de la que ahora discutimos, a la que los griegos llamaron «geometría» en tanto que «medición de la tierra». Cuán necesaria es su eficacia para los hombres puede colegirse fácilmente por cualquiera que conciba en su mente la división de la tierra. Pues en los primeros encuentros racionales entre los hombres, cuando la justicia política se aseguró de que el hombre ocupara la tierra no invadiéndola tiránicamente sino utilizando cierta medida, se estableció final-

24 Existe una clara similitud entre esta expresión y la que aparece en Pedro Abelardo, Carmen ad Astralabium, línea 986 (cit. Burnett, C., «Adelard, Music and the Quadrivium», en C. Burnett ed., Adelard of Bath, an English Scientist and Arabist of the early 12th. century, Warburg Institue Surveys and Texts, XIV, London, 1987, pp.71, n. 6). 
mente que cada persona pusiera un límite al territorio de su ocupación. Con ello se logró que cesaran tanto los litigios surgidos de la ausencia inicial de límites, como las guerras que habían comenzado por las mismas razones. Sabiendo esto e imitando la invención, otras naciones consiguieron condiciones favorables y, al tiempo, se quedaron admiradas del genio de su inventor. Aconteció, sin embargo, que algunas veces las posiciones de los términos fueron destruidas por algunos movimientos repentinos: así, las acumulaciones de arena en Libia, y ciertamente las avenidas del Nilo que inundan Egipto, borraron los vestigios de las señales mencionadas anteriormente. Sucedió entonces que cierto hombre sabio, ${ }^{25}$ distinguido por la sutileza de su mente, se condujo a un lugar secreto, y sopesando cómo podría lograrse el calculo de una regla por siempre permanente para la medida de la tierra, le fue posible evocar incluso aquello que su alma había poseído desde un principio en el tesoro de su propia divinidad.

Así, este hombre, cumpliendo su gran deseo y auxiliado por esta doncella, comenzando con el punto y ascendiendo a través de la línea, alcanzó el cuerpo sólido por medió de la superficie. Después, con esta guía, alcanzó a descubrir con cuántos puntos se obtiene una línea, con cuántas líneas una superficie, con cuántas superficies se hace perfecto un sólido. Consecuentemente, dividió el mundo en partes, las partes en provincias, las provincias en regiones, las regiones en lugares, los lugares en territorios, los territorios en campos, los campos en hectáreas, las hectáreas en varas, observando con diligencia qué es un centro, qué un diámetro, qué un perímetro, qué un ángulo, qué un base, qué un cateto, qué una hipotenusa, qué una pendiente. Por último, interesándose en una especulación de tanta complejidad, con el uso de la geometría también calculó el tamaño de cuerpos alejados. Como resultado de esto, propuso otras reglas por las cuales pudieran hallarse, sin necesidad de un ayudante, la altura de un cuerpo, el largo y ancho de un plano y la profundidad de los pozos. Puesto que esto puede parecerte increíble, no vacilaré en proponerte unos pocos ejemplos de entre los muchos posibles, ${ }^{26}$ para que juzgues que no es imposible que ello pueda hacerse y, tras haber probado un poco de esto, para que no te desvíes de semejante facultad de la inteligencia.

Se te plantea la medición de una torre de una altura cualquiera. Toma entonces una caña que mida el doble de la estatura del que mide, en su punto medio empléate en unir en ángulo recto otra caña de la mitad de tamaño que la anterior, esto es, de igual estatura que quien mide. Este instrumento se moverá alrededor del plano de la torre, hasta tanto el que mide vea claramente por encima de su cabeza el extremo superior de la torre a través del extremo superior de la caña. Visto lo cual, la altitud de la torre ha de ser juzgada en cuanto 
que a la distancia desde el que mide hasta el pie de la torre, le sea añadida la longitud del que mide. Es decir: sea la estatura del que mide $A B$, la caña del doble de su estatura $\mathrm{CD}$, la colocada en ángulo recto $\mathrm{EF}$, la altura de la torre $\mathrm{GH}$. Pues la longitud de $\mathrm{BH}$ con el añadido de BA será lo mismo que $\mathrm{GH}$, a condición de que se evite algo tan peligroso como que la anomalía del terreno impida el cálculo, lo que con ingenio sagaz se puede determinar mediante la extensión de una cuerda sobre el área.

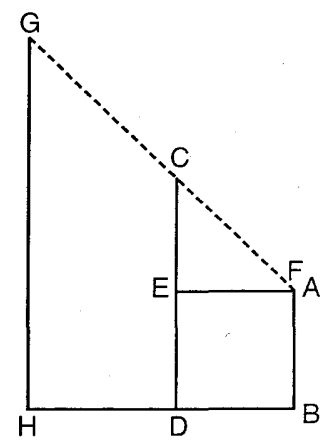

Otro modo geométrico de resolver el mismo problema no es menos evidente. Considérese una altura cualquiera desde el final de la sombra de ella misma. Cuando esto ha sido observado con cuidado, ha de clavarse al final mismo de la sombra una vara de cualquier longitud y, con no menos cuidado, ha de medirse la sombra de la vara. Pues, bien, la proporción que hay entre una y otra sombra es la misma que se obtiene entre una y otra altura. Por ejemplo: sea la altitud medida $\mathrm{AB}$ y su sombra $\mathrm{CD}$, la caña $\mathrm{EF}$, la sombra de la caña $\mathrm{GH}$. Sea $\mathrm{CD}$ el doble de GH. AB también será el doble de EF.
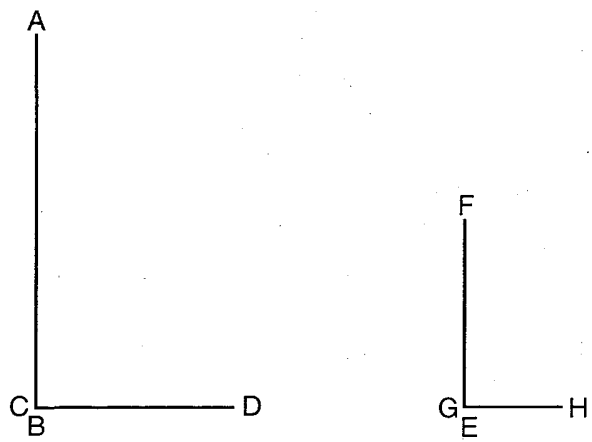

No obstante, para una superficie plana, a la que los griegos denominan «epiphania», usamos este método. El que mide se sitúa de pie en el borde mismo de la superficie, situando delante de sí una caña más corta que la estatura del que mide. Y así, muévase la caña alrededor de la superficie hasta que se observe el 
final de la superficie a través del extremo superior de la caña. Láncese una cuerda en ángulo recto desde el extremo superior de la caña hasta el cuerpo del que está midiendo, y señálese apropiadamente el lugar de la estatura a que apunta esta línea. Y así como la parte de estatura desde donde se ha señalado siempre será la misma que la que se forma con respecto a su ángulo recto, sin género de duda, toda la estatura lo será con respecto al plano determinado. Para hacerlo comprensible: sea el plano BF, la caña DE, la estatura del que mide $\mathrm{AB}$, la cuerda en ángulo recto $\mathrm{DC}$. La diferencia entre $\mathrm{CA}$ y $\mathrm{CD}$ será proporcional a la que se da entre $\mathrm{AB}$ y $\mathrm{BF}$.

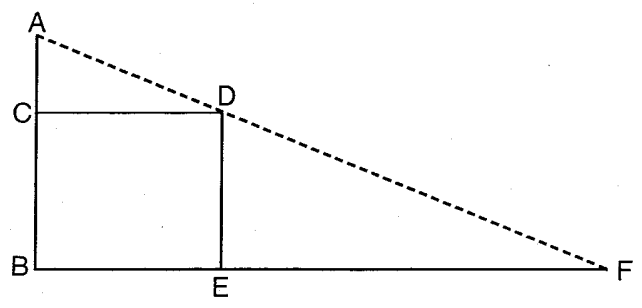

Otro modo de hacer lo mismo. Sitúese en el extremo de la superficie una caña del tamaño de quien mide, a la que se une perpendicularmente otra de cualquier longitud, así unidas, muévase este instrumento de arriba abajo hasta que, a través del extremo superior de ambas, se distinga el final de la superficie. Observado esto, examínese atentamente la unión de las cañas. Después, hay que comparar esa parte de la caña fija que queda encima de la unión con el total de su longitud, y obtendremos necesariamente la misma relación que existe entre la caña horizontal y la superficie. Para hacerlo evidente: sea AC la caña del que va a medir visualmente. Sea CE la superficie a medir y BD la caña dispuesta perpendicularmente. Sea AB la mitad de AC. En consecuencia, $\mathrm{BD}$ será la mitad de $\mathrm{CE}$, cosa que no se le ocultará a quien lo experimente.

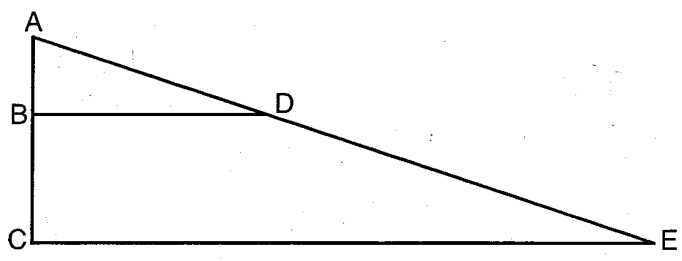

Con no menos sutileza esta doncella instruye sobre la medición de un pozo, cualquiera que sea su profundidad. Primero, el que mide tanteará con no menos exactitud que el brocal del pozo es circular; después, tómese la medida de su diámetro; por último, el que mide, situándose sobre el brocal del pozo, coloca a sus pies una vara de madera de cualquier longitud que mueve 
hacia delante y hacia atrás hasta que distinga la parte profunda del pozo a través del extremo de la vara. Luego, compárese la parte de la vara que sobresale por el brocal del pozo con la estatura del que mide, y esta será la misma que hay entre el diámetro y la profundidad del pozo más la estatura del que mide. Por ejemplo: sea la profundidad del pozo $\mathrm{CF}$, el diámetro $\mathrm{CA}$, la estatura del que mide $\mathrm{CD}$, la vara que se compara con su estatura $\mathrm{CE}$, el otro lado del pozo AB. Sea DC el triple de CE, DF será el triple de CA.

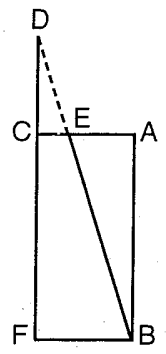

De entre muchos, estos pocos ejemplos extraje para ti, los más livianos de entre los difíciles, para que los preceptos de la Geometría sean considerados, a un tiempo, creíbles para ti y no menos inteligibles para un espíritu atento. De este modo, si alguien es instruido en estos y los demás preceptos de la Geometría, con su ingenio preparará un camino que le lleve al cielo a través de la tierra, y comprenderá la magnitud y las diferencias entre los cuerpos celestes. Y con esto es suficiente. En cuanto a la doncella que resta, cuya estatura es mayor que la del resto, te hablaré brevemente.

(ASTRONOMÍA) Esta doncella que ves, brillando con esplendor y como cubierta de ojos ${ }^{27}$ por todo su cuerpo, llevando una regla en la mano derecha y un astrolabio en la mano izquierda, explica a los que son inteligentes cualquier magnitud móvil y celeste que está contenida bajo el aplanos. ${ }^{28}$ Así, la disciplina de esta doncella describe la forma del mundo, la magnitud y el número de los círculos, las distancias de las órbitas, las trayectorias de los planetas, la situación de los signos del zodiaco; dibuja los paralelos y los coluros, divide el zodiaco en doce partes de un modo muy razonable, no ignora la magnitud de las estrellas, la oposición entre los polos ni la extensión entre los ejes. Si alguien pudiera apropiarse de ella, en modo alguno ignoraría el estado presente de las cosas inferiores, pero tampoco sus condiciones pasadas o futuras. Pues aquellos seres superiores y divinos son la causa y el principio de las naturalezas inferiores. Y de ella propondría muchas otras cosas no menos deseables que las

27 Véase Marciano Capella, De nuptiis Philologiage et Mercurii, ed. J. Willis, Leipzig, 1983, VIII, 811.

28 Aplanos es la «esfera de las estrellas inmóviles» (cf. Macrobio, Commentarii in Somnium Scipionis, ed. J. Willis, Leipzig, 1970, I, 6, 21; I, 9, 10; I, 11, 6). 
que he propuesto, pero no pueden ser abarcadas en una discusión tan breve, y para alguien inexperto en este arte, no son INTELIGIBLES. ${ }^{29}$

Mas tú, joven, ipon todo tu empeño en lo que has comenzado y abraza las enseñanzas de estas doncellas que te he definido! Pues, ejercitado en estas honrosas disciplinas, en la juventud te verás orientado por el freno de la razón y, en la vejez, verás reconfortada con alegría su carga (que así la llaman algunos). En realidad, ¿qué hay más hermoso en la juventud, fácil imitadora de vicios, que poseer eso mismo con que poder atemperarla de los vicios y aplicarla a la virtud? Y en la vejez, es cierto, ¿cuál es el modo naturalmente susceptible para la virtud, sino el de reconducir a los extraviados - y a los jóvenes - y devolverlos al buen camino? Pues en este camino, tanto la edad como el carácter comienzan a brillar con hermosura, honrados por una virtud acorde a ellos. Sin embargo, puesto que estas mismas doncellas que alabo no se encuentran fácilmente todas ellas entre las mismas personas, merecerá la pena consultar a los doctores de los diferentes pueblos y aprender de memoria lo que encontrarás muy delicadamente expresado en cada uno de ellos. Pues lo que ignoran los estudios franceses, los transalpinos lo harán accesible; lo que no aprenderás entre los latinos, la elocuencia griega te lo enseñará. Porque, así como el alma, administradora de los cuerpos, no puede ejercer todos sus poderes en todas las partes del cuerpo humano, sino que ejerce uno en la cabeza, otro en el corazón, y aún otro en el hígado, y ha asignado también distintos oficios a diversas partes de la cabeza - así, en la parte frontal imagina, en la mitad utiliza la razón y en la popa, esto es, en el cogote, esconde la memoria; ${ }^{30}$ del mismo modo, dispuso la parte izquierda del corazón para producir las arterias y la parte derecha para acoger a las venas, y también en el hígado mismo, donde siente apetito, a través de la bilis amarilla, que es cálida y seca, retiene, a través de la bilis negra, que es fría y seca, digiere, por medio de la sangre, que es cálida y húmeda, y expele, por medio de la flema, que es fría y húmeda - así, la misma administradora, supuesto que no cualquier región es fecunda para los hombres susceptibles de cualquier tipo de habilidad, estableció distintos saberes para distintos pueblos, pues lo mismo que un cuerpo puede ser más apropiado que otro para recibir la divinidad del alma, del mismo modo, lo que ella sea capaz de hacer en cierta parte del mundo, pueda lograrlo en el mundo como unidad.

Dichas estas palabras, Philosophia se alejó junto a sus doncellas con pasos moderados. Yo, por mi parte, bastante aturdido por las cosas que había oído, volví a casa, y desde ese momento consagré mi ánimo muy profundamente a cada una de las artes, y leída por completo una lección, con mayor afecto de-

29 En mayúscula en el original.

30 Cf. Nemesio, o.c., c. 13, pp. 89-90; Constantino Africano, Pantegni, Theorica, en Omnia Opera Ysaac, Lyon, 1515, VI, 11; Guillermo de Conches, Dragmaticon, ed. Ronca, VI, 18, p. 240. 
seaba otra, como si al faltar lo que restaba nada me aportara lo recogido, esperando que este plan pudiera moderar mi juventud y reconfortar mi vejez. Y ciertamente así hice yo cuando, viviendo de Salerno, en la Magna Grecia expuse estas opiniones a cierto filósofo griego que sobresalía, por encima de las demás artes, en las artes de la medicina y de la naturaleza de las cosas; preguntándole por qué causa los imanes atraen el hierro, él mismo, a su vez, me proponía una cuestión a la solución dada sobre este asunto y otros similares, diciendo: «Te pregunto, ¿si se abriera un agujero de grosor suficiente a través de la mitad del globo terráqueo y se arrojarse con energía una piedra de no poco peso, en qué dirección escaparía, puesto que los cuerpos pesados ni pueden ascender al cielo ni es posible que haya algo en el curso de la caída que pueda detener este peso? ${ }^{31}$ Cuando, a su vez, escuchó mi respuesta a la pregunta formulada, al final de nuestra discusión le oí afirmar que uno nunca lamentaría estudiar las artes liberales ni el esfuerzo que suponen. Al haberme expuesto esto a mí, y no comprendiendo bien lo que significaba, me dijo: «Efectivamente, quien abandonadas las cosas y se conduce a un lugar secreto, reforzado por virtudes purgativas, rechazando aquellos encantos de las cosas mundanas, ciertamente nunca odia lo aprendido - por el contrario, frecuentemente se reprocha no haber bebido más profundamente de esa fuente».

Hasta aquí, queridísimo sobrino, te he explicado con gran empeño la causa de mi sinuoso itinerario a través de los maestros de distintas regiones, para liberarme de la carga de tu injusta acusación y disponerte favorablemente a estos estudios, para que cuando los demás hayan exhibido sus tesoros de muchas maneras, nosotros propongamos ciencia. Adiós, y juzga por ti mismo si hemos disputado de manera correcta.

\author{
Pedro Mantas España \\ Colaborador Dpto. Filosofía \\ Universidad de Córdoba \\ Plaza del Cardenal Salazar, 3 \\ E-14.071 - CÓRDOBA
}

